\title{
PENGARUH BI RATE DAN NILAI TUKAR MENGAMBANG OLEH BANK INDONESIA TERHADAP TINGKAT INFLASI DI INDONESIA TAHUN 2008 - 2015
}

\author{
Anna Nurfarhana, Tri Anita \\ Program Studi Pendidikan Ekonomi \\ Fakultas Ilmu Pendidikan dan Pengetahuan Sosial \\ Universitas Indraprasta PGRI \\ Email: annanurfarhana788@gmail.com
}

\begin{abstract}
The purpose of this study is to examine the effect of $\mathrm{Bl}$ rate and exchange rate on inflation rate in Indonesia. Based on the results of multiple regression analysis shows that the proposed hypothesis is rejected if it does not take into account the time lag, in accordance with the results of data processing with SPSS. However, if the data processing considers the time lag, in as such the result of data processing with E Views, the proposed hypothesis is accepted.Based on the results of research and analysis discussed in chapter IV, it can be concluded as follows: there is significant effect of Bl Rate and floating exchange rate by Bank of Indonesia towards inflation rate. It is proved by sig $0.000<$ 0,05 and $F_{h} 45,932$, there is no significant effect of Bl Rate to inflation level. It is proved by sig 0,000 $<0,05$ and $t_{h} 8,822$, there is no significant effect of floating exchange rate by Bank Indonesia to inflation rate. This is evidenced by sig 0.116 and $t_{h} 1.586$. With $E$ Views processing, it can be concluded that: there is significant effect of BI Rate on inflation rate. This is evidenced by sig 0.0219 $<0.05$ and $t_{h}-2.3369$ and there is a significant effect of floating exchange rate by Bank of Indonesia on the inflation rate. This is evidenced by sig $0.0429<0.05$ and $t_{h} 2.0556$.
\end{abstract}

Keyword: BI rate, Exchange rate, Inflation rate

\begin{abstract}
ABSTRAK
Tujuan dari penelitian ini adalah untuk meneliti pengaruh Bl Rate dan nilai tukar terhadap tingkat inflasi di Indonesia. Berdasarkan hasil analisis regresi berganda menunjukkan bahwa hipotesis yang diajukan ditolak jika tidak memperhitungkan jeda waktu (time lag), sesuai dengan hasil pengolahan data dengan SPSS. Akan tetapi, jika pengolahan data memperhitungkan time lag seperti hasil pengolahan data dengan $\mathrm{E}$ Views, maka hipotesis yang diajukan diterima. Berdasarkan hasil penelitian dan analisis yang telah dibahas dalam bab IV, maka dapat disimpulkan hal-hal sebagai berikut: terdapat pengaruh yang signifikan B1 Rate dan Nilai Tukar mengambang oleh Bank Indonesia terhadap tingkat inflasi. Hal tersebut dibuktikan dengan sig $0,000<0,05$ dan $F_{h} 45,932$, terdapat pengaruh yang tidak signifikan Bl Rate terhadap tingkat inflasi. Hal tersebut dibuktikan dengan sig $0,000<0,05$ dan $t_{h} 8,822$, terdapat pengaruh yang tidak signifikan nilai tukar mengambang oleh Bank Indonesia terhadap tingkat inflasi. Hal tersebut dibuktikan dengan sig 0,116 dan $t_{h}$ 1,586. Dengan pengolahan Eviews, dapat disimpulkan bahwa :terdapat pengaruh yang signifikan BI Rate terhadap tingkat inflasi . Hal tersebut dibuktikan dengan sig 0,0219<0,05 dan $t_{h}-2,3369$ dan terdapat pengaruh yang signifikan nilai tukar mengambang oleh Bank Indonesia terhadap tingkat inflasi. Hal tersebut dibuktikan dengan sig $0,0429<0,05$ dan $\mathrm{t}_{\mathrm{h}} 2,0556$.
\end{abstract}

Kata kunci : BI rate, Nilai tukar mengambang oleh BI,Tingkat inflasi 


\section{PENDAHULUAN}

Pada dasarnya, Bank Indonesia memiliki tujuan untuk mencapai dan memelihara kestabilan nilai rupiah agar perekonomian berjalan stabil sebagaimana tercantum dalam UU No.3 Tahun 2004 Pasal 7 tentang Bank Indonesia.

Kestabilan nilai rupiah tersebut antara lain adalah kestabilan terhadap harga-harga barang dan jasa yang tercermin pada inflasi. Untuk mencapai target tersebut, sejak 2005 , Bank Indonesia menerapkan kerangka kebijakan moneter dengan inflasi sebagai sasaran utama kebijakan moneter (Inflation Targeting Framework) dengan menganut sistem nilai tukar yang mengambang (free floating). Peran kestabilan nilai tukar sangat penting dalam mencapai stabilitas harga dan sistem keuangan. Oleh karena itu, Bank Indonesia juga menjalankan kebijakan nilai tukar untuk mengurangi volatilitas nilai tukar yang berlebihan, bukan untuk mengarahkan nilai tukar pada level tertentu.

Dalam pelaksanaannya, Bank Indonesia sebagai otorita moneter memiliki kewenangan untuk melakukan kebijakan moneter melalui penetapan sasaran-sasaran moneter (seperti jumlah uang beredar atau suku bunga) dengan tujuan utama menjaga agar laju inflasi yang ditetapkan oleh Pemerintah dapat terkendali.

Karena itu kestabilan inflasi juga merupakan prasyarat bagi pertumbuhan ekonomi yang berkesinambungan yang pada akhimya memberikan manfaat bagi peningkatan kesejahteraan masyarakat. Pentingnya pengendalian inflasi didasarkan pada pertimbangan bahwa inflasi yang tinggi dan tidak stabil memberikan dampak negatif kepada kondisi sosial ekonomi masyarakat.

Pertama, inflasi yang tinggi akan menyebabkan pendapatan riil masyarakat akan terus turun sehingga standar hidup dari masyarakat turun dan akhirnya menjadikan semua orang, terutama orang miskin, bertambah miskin.

Kedua, inflasi yang tidak stabil akan menciptakan ketidakpastian (uncertainty) bagi pelaku ekonomi dalam mengambil keputusan. Pengalaman empiris menunjukkan bahwa inflasi yang tidak stabil akan menyulitkan keputusan masyarakat dalam melakukan konsumsi, investasi, dan produksi, yang pada akhimya akan menurunkan pertumbuhan ekonomi.
Ketiga, tingkat inflasi domestik yang lebih tinggi dibanding dengan tingkat inflasi di negara tetangga menjadikan tingkat bunga domestik riil menjadi tidak kompetitif ,sehingga dapat memberikan tekanan pada nilai rupiah.

Sebagaimana yang telah dikemukakan sebelumnya bahwa Bl Rate dan Nilai Tukar sangat memengaruhi tingkat inflasi di Indonesia. Maka, penulis merumuskan masalah penelitian ini sebagai berikut :

1. Apakah terdapat pengaruh BI Rate dan nilai tukar mengambang secara bersama - sama terhadap tingkat inflasi di Indonesia?

2. Apakah terdapat pengaruh BI Rate terhadap tingkat inflasi di Indonesia?

3. Apakah terdapat pengaruh nilai tukar mengambang terhadap tingkat inflasi di Indonesia?

\section{Pengertian BI Rate}

Bl Rate merupakan suku bunga dengan tenor satu bulan yang diumumkan oleh Bank Indonesia secara periodik yang berfungsi sebagai sinyal (stance) kebijakan moneter. Secara sederhana, Bl Rate merupakan indikasi level suku bunga jangka pendek yang diinginkan Bank Indonesia dalam upaya mencapai target inflasi.

Bl Rate digunakan sebagai acuan dalam operasi moneter untuk mengarahkan agar Suku Bunga SBI 1 bulan hasil lelang Operasi Pasar Terbuka (OPT) berada di sekitar Bl Rate. Selanjutnya suku bunga $\mathrm{Bl}$ Rate diharapkan memengaruhi suku bunga Pasar Uang Antar Bank (PUAB), suku bunga simpanan, dan suku bunga lainnya dalam jangka waktu yang lebih panjang. Penetapan respon kebijakan moneter biasa dilakukan dalam Rapat Dewan Gubernur (RDG) triwulanan (Januari, April, Juli dan Oktober) untuk berlaku selama triwulan berjalan. Apabila diperlukan, perubahan Bl Rate juga dapat dilakukan dalam RDG bulanan. Dalam setiap RDG triwulanan yang dilakukan asesmen menyeluruh terhadap kondisi makro ekonomi, prakiraan inflasi, dan penentuan respon kebijakan moneter. Dalam RDG bulanan, review atas perkembangan inflasi, nilai tukar, dan kondisi moneter dan likuiditas di pasar dilakukan untuk memonitor dan meniiai apakah sesuai dengan prakiraan yang dilakukan dalam RDG triwulanan. Perubahan Bl Rate dilakukan dalam keiipatan 25 bps (perubahan dapat 25, 50 
ataupun 75 bps sesuai dengan situasi moneter yang terjadi).

Bl Rate ditetapkan oleh Dewan Gubemur Bank Indonesia dengan mempertimbangkan rekomendasi Bl Rate yang dihasilkan oleh fungsi reaksi kebijakan dalam model ekonomi untuk pencapaian sasaran inflasi. Selain itu Bl Rate yang ditetapkan juga mempertimbangkan berbagai informasi lainnya seperti leading indicators, survei, informasi anekdotal, variable informasi, expert opinion, asesmen faktor risiko dan ketidakpastian serta hasil-hasil riset ekonomi dan kebijakan moneter.

Respon kebijakan moneter (BI Rate) ditetapkan berlaku sampai dengan RDG berikutnya. Penetapan respon kebijakan moneter (Bl Rate) dilakukan dengan memperhatikan efek tunda kebijakan moneter (lag of monetary policy) dalam mempengaruhi inflasi. Dalam hal terjadi perkembangan di luar prakiraan semuia, penetapan stance Kebijakan Moneter dapat dilakukan sebelum RDG Bulanan melalui RDG Mingguan.

Bl Rate diumumkan ke publik segera setelah ditetapkan dalam RDG. Langkahlangkah dimaksud ditujukan untuk meningkatkan efektivitas tata kelola (governance) kebijakan moneter dalam mencapai kestabilan harga sebagai elemen sasaran akhir kebijakan ekonomi makro yang menyeluruh (social welfare).

\section{Pengertian Nilai Tukar}

Hubungan Nilai Tukar dengan Suku Bunga Nilai tukar merupakan salah satu indikator kestabilan suatu negara. Nilai tukar valuta asing adalah harga di mana pembelian dan penjualan valuta asing berlangsung. Nilai tukar merupakan jumlah mata uang dalam negeri yang harus dibayarkan untuk mendapatkan satu unit mata uang asing (Lipsey, 1992).

Permintaan valuta asing tumbuh karena kebutuhan impor barang dan jasa, pembayaran bunga dan cicilan utang serta kebutuhan individu lainnya. Di sisi lain, penawaran valuta asing timbul karena penukaran devisa hasil ekspor barang dan jasa, penarikan pinjaman luar negeri dan lain-lain. Permintaan dan penawaran valuta asing timbul karena alasan komersial dan non komersial. Alasan komersial dilandasi oleh kebutuhan transaksi perdagangan inernasional barang dan jasa, adanya lalu lintas modal asing dan spekulasi nilai tukar. Sedangkan alasan non komersiai biasanya lebih menjadi dasar bagi setiap transaksi yang dilakukan bank sentral. Nilai tukar mengambang memiliki kerapuhan yang tinggi karena sangat bergantung pada paritas daya beli (puchasing power parity). Nilai tukar paritas daya beli adalah nilai tukar yang mempertahankan tingkat harga yang relatif konstan di dua negara bila diukur dengarr mata uang bersama (Lipsey, 1992).

Dalam perekonomian terbuka dengan arus modal yang bebas, meningkatnya aliran modal masuk akan menyebabkan apresiasi nilai tukar (nilai mata uang dalam negeri menjadi lebih besar temadap mata uang luar negeri) (Susilowati dan Tjahyono, 1998). Terapresiasinya nilai tukar akan menurunkan ekspor sedangkan impor akan mengalami peningkatan. Akibatnya permintaan agregat akan turun, demikian juga laju pertumbuhan dan inflasi akan menuang (Hartadi dan Warjiyo, 1998).

Di atas sudah sempat disinggung mengenai konsep paritas daya beli (puchasing power parity), berikut ini akan dijelaskan secara khusus konsep tersebut:

\section{a. Pengertian Paritas Daya Beli (Purchasing Power Parity) \\ Konsep Purchasing Power Parity, atau} Paritas Daya Beli, PPP diperkenalkan oleh ekonomi klasik bernama David Ricardo. Konsep ini kemudian dipopulerkan oleh ekonom Swedia yang bernama Gustave Cassel pada tahun 1920, saat negara-negara Eropa seperti Jerman, Soviet, dan Hongaria mengalami inflasi tinggi.

Penjelasan konsep teori Purchasing Power Parity didasarkan pada hukum satu harga, the law of one price yang menyatakan bahwa harga komoditas yang sama di dua negara yang berbeda akan sama jika dinilai dengan mata uang yang sama.

\section{b. Paritas Daya Beli Absolut}

Dengan mengunakan konsep hukum satu harga, maka dapat dihitung seluruh harga dari sekumpulan komoditas dan jasa yang sama untuk dua negara yang berbeda, misal untuk di Amerika maupun di Jepang dapat ditulis persamaan berikut $: P J P Y=$ USD/JPYxPUSD (persamaan 1)

PJPY merupakan harga sekumpulan komoditas dan jasa yang sama di Jepang dan PUSD merupakan harga sekumpuian komoditas dan 
jasa yang sama Amerika. Sedangkan USD/JPY adalah nilai tukar Dollar Amerika terhadap Yen Jepang. Persamaan 1 adalah bentuk absolut dari kondisi paritas daya beli yang dapat dimodifikasi untuk mendapatkan hubungan antara nilai tukar kurs dengan harga sekelompok produk atau barang dari dua negara. Sehingga persamaan 1 menjadi: USD/JPY = PJPY/PUSD

Konsep paritas daya beli dalam bentuk absolut melalui persamaan 1 dapat menjelaskan terbentuknya nilai tukar valuta asing suatu negara. Dari persamaan 1 dapat diketahui bahwa nilai tukar Dollar Amerika terhadap mata uang Yen Jepang ditentukan oleh harga komoditas dan jasa dari dua negara tersebut. Pada umumnya harga sekumpulan komoditas dan jasa dinyatakan dalam indeks harga.

Konsep paritas daya beli dalam bentuk absolut mampu menjelaskan mekanisme terbentuknya kurs valuta asing secara sedemana. Namun demikian, Kesederhanaan ini menjadi kelemahan dalam menentukan harga sekumpulan komoditas dan jasa yang sama dari dua negara yang berbeda.

Teori PPP absolut sering kali dipandang tidak realistis karena tidak mempertimbangkan biayabiaya yang timbul untuk suatu produk seperti, biaya transportasi, biaya transaksi, tarif, dan kuata. Oleh karena itu dikembangan teori PPP relatif yang menyatakan bahwa harga komoditas yang sama akan berbeda karena ketidaksempurnaan pasar yang disebabkan oleh banyak faktor, seperti biaya transportasi, biaya transaksi, tarif atau pajak, kuota dan lainnya.

\section{c. Paritas Daya Beli Relatif}

Menurut teori PPP relatif, kurs valuta asing akan berubah untuk mempertahankan daya belinya. Kurs akan selalu berubah sesuai dengan perubahan tingkat inflasi yang terjadi di dalam suatu negara. Perubahan dimulai dari suatu kesetimbangan tertentu. Kemudian harga mengalami perubahan selama periode tertentu, bisa satu bulan, satu tahun, atau lebih lama.

\section{d. Penyederhanaan Persamaan Teori PPP Relatif}

Harga sekelompok komoditas pada awal keseimbangan dapat dinyatakan dengan PJPY untuk komoditas di Jepang dan PUSD untuk harga sekelompok komoditas di Amerika. Inffasi di Jepang dapat dinyatakan dengan iJPY dan inflasi di Amerika dinyatakan dengan iUSD. Perubahan harga sekelompok komoditas setelah dipengaruhi oleh inflasi adalah PJPY $(1+\mathrm{iJPY})$ dan PUSD ( $1+\mathrm{iUSD})$.

\section{Teori-Teori tentang Inflasi}

Menurut Bodie dan Marcus (2001:331) inflasi merupakan suatu nilai dimana tingkat harga barang dan jasa secara umum mengalami kenaikan. Inflasi adalah salah satu peristiwa moneter yang menunjukkan suatu kecenderungan akan naiknya harga-harga barang secara umum, yang berarti terjadinya penurunan nilai uang. Penyebab utama dan satusatunya yang memungkinkan gejala ini muncul menurut Teori Kuantitas mengenai uang pada mazhab klasik adalah terjadinya kelebihan uang yang beredar sebagai akibat penambahan jumlah uang di masyarakat.

Menurut Keynes dalam The General Theory of Employment, Interest and Money, dinyatakan bahwa inflasi disebabkan oleh gap antara kemampuan ekonomi masyarakat terhadap keinginan- keinginannya terhadap barang-barang (Shapiro, 2002). Yang dimaksud dengan gap disini adalah permintaan masyarakat terhadap barang-barang lebih besar daripada jumlah yang tersedia sehingga terjadi kenaikan harga, yang kemudian dikenal dengan istilah inflationary gap.

Menurut Winardi (1995 : 235) pengertian inflasi adalah suatu kenaikan relatif dalam tingkat harga umum (Sarwoko, 2005). Inflasi dapat timbul bila jumlah uang atau uang deposito dalam peredaran banyak, dibandingkan dengan jumlah barang-barang atau jasa yang ditawarkan atau bila karena hilangnya kepercayaan terhadap mata uang nasional, terdapat gejala yang meluas untuk menukar dengan barang-barang.

Ada berbagai macam inflasi, seperti : Menurut Kusnadi (1997 :227) jenis inflasi berdasarkan atas parah tidaknya inflasi tersebut dibedakan menjadi empat macam (Sarwoko, 2005), yaitu:

a. Inflasi tingkat ringan yaitu jika tingkat inflasi dibawah 10 persen setahun.

b. Inflasi tingkat sedang yaitu jika tingkat inflasi diatas 10 persen sampai 30 persen setahun.

c. Inflasi tingkat berat yaitu jika tingkat inflasi diatas 30 persen akan tetapi masih dibawah 100 persen. 
d. Inflasi tingkat sangat parah, inflasi yang terakhir ini dikenal pula dengan nama hiperinflasi, yaitu jika tingkat inflasi diatas 100 persen.

Jenis inflasi atas dasar perbedaan kualitatif, yaitu penggolongan yang didasarkan pada perbedaan keadaan. Dalam hal ini inflasi dibagi dalam tiga tahap (Samueison dan Nordhaus, 1998 : 299), yaitu :

\section{a. Inflasi Moderat}

Bentuk inflasi ini terjadi ketika hargaharga meningkat dengan perlahan-lahan. Kita dapat mengatakan inflasi ini bersifat moderat apabila angkanya masih di bawah 10 persen setahun atau inflasi satu angka atau satu digit. Dalam situasi inflasi moderat harga barangbarang relatif tidak akan bergerak jauh menyimpang. Orang tidak akan terlalu banyak berpikir dalam menggunakan uangnya, karena tingkat suku bunga riil tidak terlalu rendah. Apabila laju inflasi rendah, maka uang yang biasanya berbunga nominal hampir mendekati noi, maksimal menghasilkan suku bunga riil sedikit negatif. Selain itu harapan yang timbul dari masyarakat relatif stabil. Orang tidak khawatir dalam membuat transaksi dengan nilai nominal.

\section{b. Inflasi Menengah (Galloping Inflation)}

Bentuk inflasi ini terjadi jika harga-harga mulai melonjak 20, WO atau 200 persen setahun artinya inflasi ini ditandai dengan kenaikan harga yang cukup besar (biasanya double digit atau triple digit), inflasi ini sering disebut dengan inflasi dua / tiga angka / digit. Begitu inflasi ganas mulai mengakar, maka gangguan ekonomi yang gawat mulai bermunculan. Pada umumnya sebagian besar kontrak-kontrak transaksi dikaitkan dengan indeks harga atau mata uang asing, dolar misalnya, uang kehilangan nilainya begitu cepat, dimana uang memperoieh suku bunga riilnya sebesar negatif 50 atau 100 persen setahun, karena itu orang tidak mau lagi menyimpan uang lebih dari jumlah minimum yang dibutuhkannya. Pasar uang akan semakin buruk dana dana biasanya diaiokasikan lebih dengan cara penjatahan daripada perhitungan suku bunga. Orang-orang berlomba-lomba dalam menimbun barang, membeli rumah, tanah, dan tidak akan pernah meminjamkan uang dengan suku bunga yang biasa.

\section{c. Hiperinflasi}

Bentuk inflasi ketiga yang sangat mernatikan disebut dengan hiperinflasi. Adapun ciri-ciri dari hiperinfiasi adalah : kecepatan perputaran uang (yaitu betapa cepat uang dibelanjakan begitu diterima) meningkat sangat besar misalnya uang akan berputar lebih dari 30 kali lebih cepat dari awal periods. Dan hargaharga relatif sangat tidak stabil, biasanya upah nil seseorang hanya berubah satu persen atau bahkan kurang dari bulan ke bulan Selain kategori-kategori inflasi di atas, jenis inflasi juga dapat dibedakan menurut sebabnya, yaitu:

1) Demand pull inflation

Inflasi ini bermula dari adanya kenaikan permintaan total. Kenaikan permintan total akan menaikkan harga dan hasil produksi.

2) Cost push inflation

Biasanya ditandai dengan kenaikan harga dan penurunan produksi. Keadaan ini timbul biasanya dimulai dengan adanya penurunan dalam penawaran total sebagai akibat kenaikan biaya produksi. Kenaikan biaya produksi pada gilirannya akan menaikkan harga dan turunnya produksi. Kalau proses ini berjalan terusmenerus timbullah cost push inflation.

\section{METODE}

Penelitian berdasarkan tujuannya yang digunakan adalah penelitian deskriptif dan eksplanatif. Penelitian deskriptif yaitu penelitian yang bertujuan untuk membuat deskripsi secana sistematis, faktual, dan akurat mengenai faktafakta dan sifat-sifat dari populasi (objek) penelitian. Sedangkan penelitian eksplanatori adalah penelitian yang bertujuan untuk menguji suatu kebenaran melalui hipotesis tentang sebabakibat antara berbagai variable yang diteliti. Dalam hal ini dengan sendirinya sudah ada hipotesisnya.

Penelitian berdasarkan sumber datanya atau tempatnya yang digunakan adalah Penelitian Kepustakaan (Library Research). Metode kepustakaan dilakukan dengan cara membaca dan menelaah literatur-literatur yang berkaitan dengan perumusan masalah. Tujuan dari penelitian kepustakaan ini adalah untuk mendapatkan data sekunder sebagai pemahaman teoritis tentang pengaruh $\mathrm{Bl}$ Rate dan nilai tukar oleh Bank Indonesia terhadap tingkat inflasi di Indonesia. 
Berdasarkan sifat datanya, penelitian yang digunakan adalah penelitian kuantitatif, yaitu metode kuantitatif sebagai prosedur penelitian yang menghasilkan data berupa angka-angka dan umumnya dianalisis dengan menggunakan statistif deskriptif atau inferensial. Metode penelitian kuantitatif digunakan untuk meneliti pada populasi atau sampel dengan menggunakan instrument penelitian dengan tujuan untuk menguji hipotesis yang telah dirumuskan.

Berdasarkan metodenya, penelitian ini merupakan penelitian korelasional, yaitu suatu penelitian yang dirancang untuk menentukan tingkat hubungan antar variabel yang berbeda berdasarkan pada koefisien korelasi.

Berdasarkan waktu pengumpulannya data yang dikumpulkan yaitu date berkala (time series), yaitu data yang terkumpul dan waktu ke waktu untuk memberikan gambaran perkembangan suatu kegiatan atau keadaan. Dalam hal ini yaitu data Bl Rate, nilai tukar (Kurs Tengah Bl IDR/USD), dan tingkat inflasi tahun 2008 - 2015.

\section{PEMBAHASAN}

Berdasarkan hasil analisis regresi berganda menunjukkan bahwa hipotesis yang diajukan ditolak jika tidak memperhitungkan jeda waktu (time lag), sesuai dengan hasil pengolahan data dengan SPSS. Akan tetapi, jika pengolahan data memperhitungkan time lag seperti hasil pengolahan data dengan E Views, maka hipotesis yang diajukan diterima.

Berdasarkan hasil penelitian dan analisis yang telah dibahas, dapat disimpulkan hal-hal sebagai berikut:

1. Terdapat pengaruh yang signifikan Bl Rate dan Nilai Tukar mengambang oleh Bank Indonesia terhadap tingkat inflasi. Hal tersebut dibuktikan dengan sig $0,000<0,05$ dan FH 45,932.

2. Terdapat pengaruh yang tidak signifikan $\mathrm{Bl}$ Rate terhadap tingkat inflasi. Hal tersebut dibuktikan dengan sig $0,000<0,05$ dan $\mathrm{tH}$ 8,822 .

3. Terdapat pengaruh yang tidak signifikan nilai tukar mengambang oleh Bank Indonesia terhadap tingkat inflasi. Hal tersebut dibuktikan dengan sig 0,116 dan tH 1,586.

Dengan pengolahan Eviews, dapat disimpulkan bahwa :
1. Terdapat pengaruh yang signifikan BI Rate terhadap tingkat inflasi. Hal tersebut dibuktikan dengan sig $0,0219<0,05$ dan $\mathrm{tH}-$ 2,3369 .

2. Terdapat pengaruh yang signifikan nilai tukar mengambang oleh Bank Indonesia terhadap tingkat inflasi. Hal tersebut dibuktikan dengan sig $0,0429<0,05$ dan $\mathrm{tH}$ 2,0556 .

\section{SIMPULAN DAN SARAN}

Berdasarkan hasil analisis pembahasan serta beberapa simpulan pada penelitian ini, adapun saran-saran yang dapat diberikan melalui hasil penelitian ini agar mendapatkan hasil yang lebih baik, yaitu :

1. Bagi peneliti selanjutnya diharapkan dapat meneliti dengan variabel-variabel lain diluar variabel ini agar memperoleh hasil yang lebih bervariatif yang dapat menggambarkan hal-hal apa saja yang dapat berpengaruh terhadap inflasi dan dapat pula memperpanjang periode amatan dan disarankan untuk memperluas cakupan penelitian tentang pengaruh bauran kebijakan (policy mix), yaitu paduan kebijakan fiskal (Pemerintah) dan moneter (Bank Indonesia) terhadap inflasi atau indikator ekonomi lainnya secara keseluruhan dengan menggunakan instrumen kebijakan lain selain variabel yang dipakai pada penelitian ini.

2. Bagi pengambil kebijakan terutama Pemerintah, untuk mengendalikan inflasi dengan pengaruh yang lebih cepat mungkin lebih tepat dilakukan oleh Pemerintah daripada Bank Indonesia. Hal ini disebabkan karena adanya time lag antara kebijakan BI Rate sebagai instrumen Bank Indonesia untuk mengendalikan inflasi. Di samping itu, efek Bl Rate yang pada akhimya hanya mempengaruhi tingkat bunga kredit perbankan hanya akan mempengaruhi tingkat permintaan (demand side). Sedangkan kebijakan untuk supply side hanya dapat dilakukan oleh Pemerintah seperti menetapkan harga BBM dan tarif listrik maupun transportasi, juga membuka keran impor untuk barang-barang kebutuhan pokok seperti beras, daging sapi, kedelai, dan lainlain untuk menurunkan harga domestik yang cukup tinggi. Contoh kebijakan-kebijakan ini mempunyai dampak sangat signifikan 
terhadap inflasi karena komponen administered price dan volatile foods merupakan dua dari tiga bagian besar dari komponen penyusun inflasi itu sendiri.

3. Bagi manajemen perusahaan, dalam pengambilan keputusan harus memperhatikan inflasi karena inflasi merupakan salah satu leading indicator kondisi perekonomian negara, dimana inflasi ini berdasarkan hasil penelitian dipengaruhi juga oleh Bl Rate dan nilai tukar, walaupun kedua variabel ini tidak berpengaruh seketika atau langsung, tetapi memerlukan jeda waktu (time lag). Oleh karena itu, disarankan untuk tidak terlalu reaktif terhadap depresiasi rupiah ataupun apresiasi rupiah khususnya jika hanya terjadi dalam waktu siagkat. Manajemen perusahaan disarankan untuk tidak segera menaikkan harga produknya ketika terjadi depresiasi untuk tetap menjaga tingkat permintaan konsumennya, karena sesuai hasil peneiitian yang menunjukkan bahwa terdapat jeda waktu (time lag) dari fluktuasi rupiah dalam mempengaruhi tingkat inflasi.

\section{DAFTAR PUSTAKA}

Hanafi. 2003. Manajemen Keuangan Internasional. Yogyakarta: BPFE

Hady H. 2004. Ekonomi Internasional, Teori dan Kebijakan Keuangan International. Buku 2 Edisi Revisi. Jakarta: Ghalia Indonesia

Martono, 2010. Bank dan Lembaga Keuangan Lain. Edisi 4. Jakarta: Penerbit Ekonisia

Pohan, Aulia. 2008. Kerangka Kebijakan Moneter dan Implementasinya. Jakarta: Rajawali Pers.

Prayitno, D. 2012. Cara Kilat Belajar Analisis Date dengan SPSS 20. Yogyakarta: Penerbit Andi

Permendiknas Nomor 46 Tahun 2009/2009. Ejaan Bahasa Indonesia yang Disempumakan. Yogyakarta: Pustaka Timur.

Sakaran, Uma, 2009. Metode Penelitian untuk Bisnis. Jakarta: Salemba Empat.
Siamat, Dahian. 2005. Manajemen Lembaga Keuangan Kebijakan Moneter dan Perbankan. Edisi Kelima. Jakarta: Fakultas Ekonomi Universitas Indonesia.

Susilo Sriet et al. 2000. Bank dan Lembaga Keuangan Lain. Jakarta: Salemba empat. Yuliadi, Imamuddin. 2009. Ekonomi Moneter, Jakarta: Indeks.

\section{Internet:}

www.bi.go.id 